This item was submitted to Loughborough's Research Repository by the author.

Items in Figshare are protected by copyright, with all rights reserved, unless otherwise indicated.

\title{
Challenges for organisational resilience
}

PLEASE CITE THE PUBLISHED VERSION

https://doi.org/10.1108/crr-01-2019-0008

PUBLISHER

(c) Emerald

VERSION

AM (Accepted Manuscript)

PUBLISHER STATEMENT

This work is made available according to the conditions of the Creative Commons Attribution-NonCommercialNoDerivatives 4.0 International (CC BY-NC-ND 4.0) licence. Full details of this licence are available at: https://creativecommons.org/licenses/by-nc-nd/4.0/

\section{LICENCE}

CC BY-NC-ND 4.0

\section{REPOSITORY RECORD}

Burnard, Kevin J., and Ran Bhamra. 2019. "Challenges for Organisational Resilience". figshare. https://hdl.handle.net/2134/38225. 


\title{
Challenges for Organisational Resilience
}

\begin{abstract}
Purpose - Organisational resilience presents complex challenges organisations must address in order to respond and recover from disruptive events. From an operations and strategic management perspective, this paper outlines these challenges and highlights the important perspectives within the growing literature of resilience.

Design/methodology/approach - Based on a critique of relevant literature this Viewpoint paper identifies and discusses the emerging challenges in developing resilience at an organisational level.

Findings - The outcome of this paper establishes a set of propositions to guide the development of organisational level resilience as well as outlining future research.

Originality/value - The outlined propositions highlight the features of both active and passive resilience and identify key considerations for organisations. Through recognising these propositions organisations may be better placed to address the impacts of disruptive events.
\end{abstract}

\section{Introduction}

Resilience has now been explored across several decades and numerous contexts (Holling, 1973; Weick \& Sutcliffe, 2001; Hamel \& Valikangas, 2003; Christopher \& Peck, 2004; Lengnick Hall \& Beck, 2005; Sheffi, 2005; Hollnagel et al. 2006; Vargo \& Seville, 2011). Within this growing narrative, resilience is often referred to as a concept related to the "capacity to absorb impact and recover" (Linnenluecke and Griffiths, 2010), or the "ability to return to stable equilibrium and avoid the tipping point" (Rudolph and Repenning, 2002). These and other definitions give rise to a complex concept composed of multiple elements in which resilience illustrates the "ability to adapt and strengthen in the face of challenge, trauma, or stress" (Gallos, 2008). However, while the concept of resilience is receiving duly increased attention, resilience still presents several challenges for organisations. Further work is still required in regards to understanding the features of resilience and the effective development of organisational level resilience.

One of the central challenges of resilience, is that the resilience of an individual element or system is not directly observed but is often the result of multiple interactions and linkages between variables. It is these interactions that foster the complex ability to address discontinuities and adversity (Burnard et al, 2018). As such, several authors (Gunderson, 2000; Sutcliffe and Vogus, 2003; Turner et al, 2003; Dalziell and McManus, 2004; Gallopin, 2006) emphasise elements such as vulnerability, awareness, robustness, resistance and recovery within their respective studies of resilience. Subsequently, rather than a discrete concept, resilience forms a construct related to the adjustment of an element or system. The diverse range of perspectives related to resilience illustrates the complexity of this construct. The associated definitions give rise to the notion of different configurations or forms of resilience, but essentially, resilience may be defined as either 'active' or 'passive'. While some definitions promote a proactive engagement and adjustment of a system in relation to change (active resilience); others highlight the ability to withstand or absorb 
disturbances (passive resilience). The notion of passive resilience emphasises resistance to impacts and developing robustness within system elements. The resilience of a system may then be characterised through the capacity to maintain structure and function during periods of adversity or following the impact of an event. While active resilience addresses the features of adjustment and change following an impact. The resilience of the system could then be defined by the ability to transition or restructure. Recognising these forms of resilience, the question is then when do systems, in this case organisations, weather the storm and when do they change?

Within the resilience literature, three dominant levels of resilience have emerged: the individual human level, the organisational level and the infrastructural/network level. Across these levels, resilience may be defined through either 'active' or 'passive' forms. Through defining the characteristics of these resilience forms, this paper aims to outline the key considerations for developing organisational resilience. Based on a review of relevant literature, the following section discusses these three levels of resilience.

\section{Levels of Resilience}

Resilience has been explored across multiple disciplines and broadly relates to a fundamental change within an element or system following an impact (Bhamra et al, 2011). Recognising this feature of change, resilience can be viewed as the capacity or capability to respond during periods of difficulty. This response may relate to a fundamental change or shift within the impacted element or system. The system may resist this change, through established elements of robustness, or it may adapt in response (Burnard et al, 2018). The associated behaviours of the element or system then provide an insight into resilience. At an individual level, these behaviours illustrates how individuals can overcome incredible adversity and trauma, or conquer the challenges of climbing Everest. At an organisational level, resilience provides a potential insight into how organisations are able to maintain function through periods of disruption and crisis. Breakdowns, supply interruptions, natural disasters, all pose a severe threat to the continued performance of organisations. At the widest scale, infrastructural resilience conceptualises how communities and regions are able to persevere and grow while facing complex challenges. The following sections explore the three levels of resilience towards understanding the various forms and characteristics of resilience.

\section{Individual Resilience}

Studies related to the disciplines of childhood development and psychology have provided significant insights and advancement into the development of individual and personal resilience. Several longitudinal studies, particularly within the context of childhood development, have explored the development of resilience within social systems (Werner, 1990; Kaplan, 1990). From this, a concept of resilience has emerged which refers to a process of adaptation in the face of significant adversity, change and stress. This response then reinforces an individual's ability to then face future adversity (Stewart et al., 1997; Luthar et al., 2000; Margalit 2004). Initially, individual resilience was considered an inherent personality trait (Anthony \& Cohler, 1987). However, as the resilience literature has evolved over recent decades, studies have increasingly acknowledged the influence of external factors which has resulted in more diverse view of 
resilience at an individual level. Reflecting this, Rutter (2012) identifies resilience as an interactive concept through which individuals are able to overcome difficulty.

\section{Organisational Resilience}

Within the organisational level, resilience provides an important insight into how organisations are able to overcome significant disruptions and maintain operations during periods of adversity. Through cultivating elements of resilience within organisational systems, several authors have suggested, that an organisation may then be better placed to then maintain or restore efficacy during challenging conditions. The capabilities or mechanisms of resilience relate to organisational features such as flexibility and redundancy (Rice Jr. \& Caniato, 2003), responsiveness, agility, velocity, visibility, supply chain management (Christopher \& Peck, 2004), and collaboration (Chen, et al., 2013).

Within an ever changing and often turbulent environment, understanding resilience and the associated capabilities is essential in development of an organisation. As the operating environment of an organisation becomes increasingly complex and uncertain, the organisation may no longer be able to effectively interpret how the environment will affect and impact performance (Yilmaz-Borekci et al, 2015). A growing perspective within this view, as highlighted by several authors (Paton et al, 2000; Dalziell and McManus, 2004; Lengnick-Hall et al, 2011), is to approach resilience from a larger system's perspective. Within this view, resilience is closely correlated with a system's ability of continuous learning, flexibility, agility, preparation, and readiness to adapt (Christopher and Peck, 2004; Ponomarov and Holcomb, 2009).

A further consideration in respect to organisational resilience is to recognise the potential implications and involvement of 'The fourth industrial revolution' or Industry 4.0. This is defined as "convergence of internet-of-things driven technologies, augmented decision making and advanced automation". Guissbauer et al (2016) reported that over $70 \%$ of the world's leading manufacturing companies expect to have advanced levels of digitisation by 2020 . The end goal here is the creation of a digital "ecosystem" in which all production aspects are digitised, and data is transparent throughout the system. Although this is beginning to happen, this will cause massive shifts in the way operations and wider supply chains are managed. Product data must be available throughout the entire network for optimised processes. With integrated value chains the location of manufacturing becomes less important. As a company becomes increasingly digitised and new technologies are introduced, a number of issues arise regarding supply chain resilience, responsiveness, effectiveness and security.

\section{Infrastructural and Supply Chain Resilience}

This paper acknowledges the large amount or research that already exists in the systems and infrastructural field so will not focus directly on these areas (Gay \& Sinha, 2013; Bocchini et al, 2014). In an interconnected world the potential impact of external forces to supply networks, in particular uncertainty and unforeseeable events (for example fuel and transport disruptions, socioeconomic disruptions, not forgetting Brexit uncertainties in the UK (Allen, 2018)), means the requirements for resilience in supply networks has never been greater. The principles of globalization, outsourcing, just in time and lean production, have previously helped to secure the 
survival and performance of organisational networks. However, the risks which come with these principles, along with the increasingly digitally-driven environment, have not yet been sufficiently addressed. Decreased material stocks, complex logistics and increased dependency on fewer suppliers has led to an increased vulnerability of supply chains. Local disruptions, e.g. from disasters, terrorism or simply the failure of a supplier, can have severe consequences for a company and its customers globally. As a result, there is an urgent need for resilient and flexible supply network paradigms.

Supply chains are constantly required to operate cost effectively and with greater efficiency. Additionally, as global supply chains and related networks have become more diverse, networks face an increasingly complex series of issues and challenges. The many facets of supply chain issues have had attempts at being addressed and highlight the need to be resilient and ensure that all partners' interests stay aligned in a collaborative network with risks managed intelligently; however, this is often very difficult (Schorpp, 2018). Existing research on methods of supplier selection has not sufficiently addressed the problem of quickly assessing several scenarios in a supply chain network. Viswanadham \& Samvedi (2013) showed how the supply chain configuration changes over the life cycle of product, wherein cheaper overseas suppliers slowly replace responsive and expensive local suppliers as the product matures. Previous research has also not practically solved the issue of rapidly re-configuring a network from a pool of potential suppliers, where response time is a competitive factor. The concept of resilience at an infrastructural and network level provides an important insight into the features and capabilities required to address these and other challenges faced by complex organisational networks.

\section{Challenges for Organisational Resilience}

For an organisation to be considered resilient, it is proposed that both active and passive resilience is required. Resilience can then be used to express the capability of an organisation to retain or restore function, and as a means to conceptualise performance in changing and often challenging environments. Passive Resilience is dependent on developing established channels of response. It is through these channels of response that the organisation is able to withstand the impacts of a disruption. To support this, organisations must recognise where resources and expertise lie. This established resource base can then be drawn on during periods of adversity. This form of resilience is strongly associated with the robustness of an organisational system, or the capacity to withstand impacts. An organisation may then be able to withstand a range of impacts while maintaining operations. The amount of impact or disruption an organisation can withstand while maintaining operations defines an organisation's capacity of passive resilience. Following the impact of an event, the configuration of an organisation may require change. Recognising this response, Active Resilience is dependent on developing effective situational awareness; establishing mechanisms and controls to monitor the external environment. This would allow an organisation to recognise changing conditions or warning signs of potential events. Defined channels of learning and decision making during periods of crisis are then essential to support response activities. Through utilising available resources and recognising contextual or situational demands, the organisation may then adapt in response to an event or perceived threat. This means that an organisation may also recognise a potential risk or threat on the horizon and then change in anticipation of a future impact. Active Resilience is subsequently associated with 
features of flexibility and agility. Within responding to an event, an organisation may follow multiple configurations of response (Burnard et al, 2018). Recognising both of these forms of resilience, it is proposed that resilience should be viewed as a dynamic capability (Teece, 2007) at an organisational level. Teece (2007) developed the idea of dynamic capabilities by naming the key characteristics as sensing (horizon scanning/understanding), seizing (actions following identification) and transforming (organisational reconfiguring). This appears to echo the three well known resilience phases of Readiness (preparation), Response (adjustment) and Recovery (adaptation).

Separating resilience into active and passive forms aids in conceptualisation. Walker et al (2002) acknowledge both active and passive elements within their definition of resilience within socioecological systems. Resilience is defined as "... the ability to maintain the functionality of a system when it is perturbed or the ability to maintain the elements required to renew or reorganise if a disturbance alters the structure of function of a system" (Walker et al, 2002). Additionally, within the context of social psychology, Pooley and Cohen (2010) suggest that resilience is the potential of an individual to exhibit resourcefulness through utilising all available resources in response to various challenges. These definitions relate to the capacity of a system or individual to withstand the impact of an event while retaining essential structures and function. If required, the system or individual is then also able to reorganise and change in response to adversity. This conceptualisation provides a more practical representation of resilience. However, reflecting this perspective within organisations presents a series of challenges.

Firstly, every organisation is unique. Organisations also face a diverse and complex series of challenges. Viewing resilience as a multi-level construct necessitates the development of organisational models that recognize this central factor. As a result, the resilience of an organisation could be defined through multiple structures or configurations. While the structure of an organisation will vary, the central features of active and passive resilience remain constant. An organisation must develop the capability to maintain function during periods of adversity, and develop the ability to effectively respond to unexpected events when required. In defining resilience at an organisational level the ability to constantly perform may indicate resilience. However, longevity is not a measure of resilience. Instead, periods of successful operation should just be viewed as periods of stability, not as a demonstration of resilience. It is during these periods, organisations should focus towards establishing the dynamic capability of resilience.

Secondly, resilience is not directly observed. It is instead the result of multiple interactions and exchanges. Within the context of an organisation, resilience relies upon the processes, structures and practices that promote various competencies, restore efficacy and support growth. Through this, resilience provides organisations with the means to mediate and overcome major disruptions (Vogus and Sutcliffe, 2007). Resilience thereby forms a multidimensional construct within organisations that results from the interactions between cognitive, behavioral and contextual elements (Lengnick-Hall and Beck, 2005). This means that at an organisational level, resilience is not defined by a single system property or resource. Several elements will contribute to the resilience of a system. The major challenge of developing resilience is then identifying and defining these elements within the functioning of an organisational system. Given the complexity 
and interconnection between organisational elements, this presents a major challenge. Additionally, every organisation will likely foster resilience differently. Meaning that two organisations may approach or respond to the same event differently. As a result, defining relevant elements related to supporting both active and passive resilience will be specific to any organisation.

Recognising this challenge, resilience highlights the need to develop capabilities towards enabling and supporting the response of an organisation prior to an event. Echoing the features of passive resilience. Developing and embedding these capabilities within organisational elements provides established competencies within the operation of an organisation. These capabilities will also be specific to each organisation and context. For these developments or improvements to become embedded, learning needs to be instilled across the organisation. This learning may then lead to future pathways of response. Through adopting a resilience led perspective, organisations may then be better able to follow robust channels of operation through promoting the continual development of competencies. Following the onset of a disruption, organisational elements are then able to draw on these capabilities and competencies when required. Subsequently, organisational resilience draws on the attributes of both active and passive resilience. Resilience thereby forms an overarching construct related to the response and adaptation of an organisation. The adaptive capacity of an organisation relates to the ability to prepare for changes and discontinuities and then respond effectively to any implications caused or related to an event (Engle, 2011). Improvement and development of an organisational system's adaptive capacity, through fostering the features of active resilience, improves the ability of a system to effectively manage the impacts of an event and alter approaches when necessary. Established prior preparations, such as business continuity planning (BCP), risk management and crisis management thereby provide a framework to structure and support response activities.

In order for an organisation to then be considered resilient, it must develop the ability to withstand disruption and reorganise in response to change. The development of passive resilience will define the tolerance of organisational elements or the amount of impact an organisation is able to effectively withstand. Active resilience requires flexibility. In responding to a direct threat or event, the challenge for an organisation is recognising the need to respond and whether they should commit organisational resources. The challenge facing organisations, is that the speed of response often determines the success of addressing and overcoming the impacts of a disruption. Once organisational elements are overwhelmed, cascading failures may be caused. The ability to contain impacts will then become significantly constrained. In viewing resilience as a multi-level construct composed of both active and passive forms, a key challenge facing organisations is then recognising the need to change. When facing a disruptive event, possibility high impact, when does an organisation need to respond and when should they adapt? This question draws on understanding the features of both active and passive resilience within an organisation.

\section{Propositions for Advancing Organisational Resilience}

In recognising resilience as involving both active and passive forms, it is proposed that organisations should view resilience as a dynamic capability related to driving organisational performance. Facing complex and often turbulent environments, organisations are continually 
challenged. Viewing resilience as a dynamic capability allows us to conceptualise and refine the ability to adapt and overcome these challenges. While the value of organisational level resilience is well recognised, resilience presents a series of challenges organisations must address in order to respond and recover from disruptive events. In addressing these challenges, three propositions are suggested for supporting the development of organisational resilience.

The ability of an organisation to respond effectively to a disruptive event lies in the ability to effectively link the features of 'active' and 'passive' resilience. As a result, organisations are capable of a range of responses to disruptive events. In developing organisational resilience it is proposed that: 1) Organisations view resilience as a dynamic capability that influences the entire organisational system. Each organisation will subsequently approach resilience in their own unique way. These approaches must recognise the outlined challenges of resilience. 2) Organisations should establish the features of passive (static) resilience. In order to develop robustness and the ability to withstand disruption, organisations must recognise available resources and identify the limitations within current operations, planning and the organisation's capacity of response. 3) Organisations must develop the features of active (dynamic) resilience. In order to respond effectively to both disruptive events and potential opportunities, organisations should develop embedded capabilities supported by effective environmental scanning and monitoring. This should form a continuous cycle of development in the organisation.

\section{Conclusion and Future Directions}

Organisations face a diverse range of risks and potential disruptions. In viewing resilience as a dynamic capability an effective response will involve several elements. This includes the ability to anticipate and understand emerging risks and threats, as well as the ability to adapt creatively to adversity. In addition, organisations must understand the established structures and operations across the organisational network (supply chain) to better support effective decision making. In order to address the impacts of an event, organisations must establish both the direct and indirect impacts of an event on the organisation and its associated infrastructures and networks. Through this organisations looking to develop organisational level resilience must develop the features of both active and passive resilience. Developing the capacity to maintain operations during periods of adversity and respond effectively to high impact events.

This paper contributes to the growing discussion related to organisational resilience. In establishing three propositions for advancing organisational resilience, the paper defines resilience as a dynamic capability composed of both active and passive forms. In exploring the challenges organisational resilience presents, a number of future directions have been identified. Future research related to resilience needs to address the issues of:

- Viewing resilience as a multi-level construct necessitates the development of organisational models that recognize this during any research that is conducted.

- Research in any one of the three basic levels of resilience - the individual human, the organisation and the infrastructural - should acknowledge the importance of the other strands and how they relate in context. 
- Organisational resilience often appears to have strong parallels with the concepts of 'dynamic capabilities' (Teece et al, 1997) and it would be worthwhile pursuing this as a research area.

\section{References}

Allen,A. (2018), Manufacturers would change supply chains due to economic nationalism, https://www.cips.org/en/supply-management/news/2018/november/manufacturerswould-change-supply-chains-due-to-economic-nationalism/

Anthony, E. J., \& Cohler, B. J. (Eds.). (1987). The invulnerable child. New York: Guilford Press.

Bhamra, R., Dani, S. and Burnard, K., 2011. Resilience: the concept, a literature review and future directions. International Journal of Production Research, 49(18), pp.5375-5393.

Burnard, K., Bhamra, R. and Tsinopoulos, C., 2018. Building organisational resilience: four configurations. IEEE transactions on engineering management, 65(3), pp. 351-362

Bocchini, P., Frangopol, D., Ummenhofer, T. and Zinke, T, (2014). "Resilience and Sustainability of Civil Infrastructure: Toward a Unified Approach”, Journal of Infrastructure Systems, 20(2).

Chen, J., Chen, T.H.Y., Vertinsky, I., Yumagulova, L. and Park, C., 2013. Public-private partnerships for the development of disaster resilient communities. Journal of contingencies and crisis management, 21(3), pp.130-143.

Christopher, M. and Peck, H. (2004), "Building the resilient supply chain", The International Journal of Logistics Management, Vol. 15 No. 2, pp. 1-13.

Dalziell, E.P. and McManus, S.T., (2004). "Resilience, vulnerability, and adaptive capacity: Implications for system performance." International Forum for Engineering Decision Making (IFED), University of Canterbury, Christchurch.

Engle, N.L., 2011. Adaptive capacity and its assessment. Global Environmental Change, 21(2), pp.647-656.

Gay, L.F., \& Sinha, S.K., (2013). "Resilience of civil infrastructure systems: literature review for improved asset management”, Int. J. Critical Infrastructures, Vol. 9, No. 4.

Gallopín, G.C., 2006. Linkages between vulnerability, resilience, and adaptive capacity. Global environmental change, 16(3), pp.293-303.

Gallos, J.V., 2008. Learning from the toxic trenches: The winding road to healthier organizationsand to healthy everyday leaders. Journal of Management Inquiry, 17(4), pp.354-367.

Geissbauer, R., Vedso, J. and Schrauf, S. (2016) 'Industry 4.0: Building the digital enterprise', Retrieved from PwC Website: https://www. pwc. com/gx/en/industries/industries4.0/landing-page/industry-4.0-building-your-digital-enterprise-april-2016.

Gunderson, L.H., 2000. Ecological resilience-in theory and application. Annual review of ecology and systematics, 31(1), pp.425-439.

Hamel, G. and Valikangas, L., (2003). "The quest for resilience." Harvard Business Review, Vol 81 (9), pp. 52-65.

Holling, C. S. (1973). "Resilience and stability of ecological systems." Annual Review of Ecology and Systematics Vol 4 pp.1-23.

Hollnagel, E. (2006) "Resilience: the challenge of the unstable." In: Hollnagel, E., Woods, D. and Leveson, N. (Eds.). Resilience engineering. Burlington (VT): Ashgate, 2006, pp. 9-18. 
Kaplan, H.B., (1990). "Toward an understanding of resilience: a critical review of definitions and models." In: M.D. Glantz and J.L. Johnson, (Eds). Resilience and development: positive life adaptation. Springer Science \& Business Media.

Lengnick-Hall, C.A., Beck, T.E. and Lengnick-Hall, M.L., 2011. Developing a capacity for organizational resilience through strategic human resource management. Human Resource Management Review, 21(3), pp.243-255.

Lengnick-Hall, C.A. and Beck, T.E., 2005. Adaptive fit versus robust transformation: How organizations respond to environmental change. Journal of Management, 31(5), pp.738757.

Linnenluecke, M. and Griffiths, A., 2010. Beyond adaptation: resilience for business in light of climate change and weather extremes. Business \& Society, 49(3), pp.477-511.

Luthar, S. S., Ciccheti, D. and Becker, B. (2000). "The Construct of Resilience: A Critical Evaluation and Guidelines for Future" WorkChild Dev. Vol 71(3): pp. 543-562.

Margalit, M., (2004). "Second-generation research on resilience: Social-emotional aspects of children with learning disabilities." Learning Disabilities Research and Practice 19(1): pp. 45-48.

Paton, D., Smith, L. and Violanti, J., 2000. Disaster response: risk, vulnerability and resilience. Disaster Prevention and Management: An International Journal, 9(3), pp.173-180.

Ponomarov, Y.S. and Holcomb, M.C. (2009), "Understanding the concept of supply chain resilience", The International Journal of Logistics Management, Vol. 20 No. 1, pp. 124143.

Pooley, J.A. and Cohen, L., 2010. Resilience: A definition in context. Australian Community Psychologist, 22(1), pp.30-37.

Rice, J.B. and Caniato, F. (2003), "Building a secure and resilient supply network", Supply Chain Management Review, Vol. 7 No. 5, pp. 22-30.

Rudolph, J.W. and Repenning, N.P., 2002. Disaster dynamics: Understanding the role of quantity in organizational collapse. Administrative Science Quarterly, 47(1), pp.1-30.

Rutter, M., (2012). "Resilience as a dynamic concept." Development and Psychopathology. Vol 24, pp. 335-344

Schorpp,G., Erhun,F. \& Lee, H.L. (2018) Multi-Tiered Supply Chain Risk Management, Stanford University Working Paper No. 3639.

Sheffi, Y. (2005). "Building a resilient supply chain". Harvard Business Review. Vol 1 (8), pp. 1-4. Stewart et al., 1997;

Sutcliffe and Vogus, 2003;

Stewart, M., Reid, G. and Mangham, C., (1997). Fostering Children's Resilience. Journal of Pediatric Nursing, 12 (1), pp. 21-31.

Teece, D.J. (2007), "Explicating dynamic capabilities: the nature and micro foundations of (sustainable) enterprise performance", Strategic Management Journal, Vol. 28, pp.

Vargo, J. and Seville, E., 2011. Crisis strategic planning for SMEs: finding the silver lining. International Journal of Production Research, 49(18), pp.5619-5635.

N Viswanadham, A Samvedi, (2013). Supplier selection based on supply chain ecosystem, performance and risk criteria, International Journal of Production Research, 51(21). 
Vogus, T.J. and Sutcliffe, K.M., (2007). "Organizational resilience: towards a theory and research agenda." In: IEEE international conference on systems, man and cybernetics, ISIC, pp. 7-10. October, Montreal, 3418.

Walker, B. H., Carpenter, S., Anderies, J. M., Abel, N., Cumming, G. S., Janssen, M. A., Lebel, L., Norberg, J., Peterson, G. D., Pritchard, R., (2002). "Resilience management in socialecological systems: a working hypothesis for a participatory approach." Conservation Ecology, Vol 6 (1), 14.

Weick, K.E. and Sutcliffe, K.M. (2001). Managing the Unexpected: Assuring High Performance in an Age of Complexity. Jossey-Bass, San Francisco.

Werner, E. E. (1990). "Protective factors and individual resilience." In: Shonkoff, J. P., Meisels, S. J., (2000). Handbook of Early Childhood Intervention. 2nd Ed. Cambridge University Press, ISBN-13: 978-0521585736 ISBN-10: 0521585732.

Yilmaz-Börekçi, D., İşeri Say, A. and Rofcanin, Y., 2015. Measuring supplier resilience in supply networks. Journal of Change Management, 15(1), pp.64-82. 